\title{
The Pattern of Policy Change on Disaster Management in China: A Bibliometric Analysis of Policy Documents, 1949-2016
}

\author{
Qiang Zhang ${ }^{1,2,3} \cdot$ Qibin Lu $^{1,2} \cdot$ Deping Zhong ${ }^{2} \cdot$ Xuanting Ye $^{4}$
}

Published online: 16 March 2018

(C) The Author(s) 2018

\begin{abstract}
This article presents a comprehensive review of China's policy system for the management of natural hazard-induced disasters from 1949 to 2016 through a quantitative bibliometric analysis of 5472 policy documents on such disasters. It identifies four phases of China's evolving disaster management system, which focused on agriculture, economic development, government and professional capacity building, and disaster governance, respectively. Characteristics of policies and contributing factors of policy change in each of the four phases are discussed in depth. This article provides a quantitative foundation for understanding the dynamic policy change of the disaster management system in China with a particular emphasis on the governance capacity and may serve as a basis for exploring the potential pathways of transformation according to the Sendai Framework for Disaster Risk Reduction 2015-2030 and the Sustainable Development Goals.
\end{abstract}

Keywords Bibliometric analysis - China - Disaster governance $\cdot$ Disaster management $\cdot$ Policy change $\cdot$ Policy document

Qibin Lu

luqibin@bnu.edu.cn

1 School of Social Development and Public Policy, Beijing Normal University, Beijing 100875, China

2 Innovation Center for Risk Resilience, Beijing Normal University, Beijing 100875, China

3 Center for Crisis Management Research, Tsinghua University, Beijing 100084, China

4 School of Management and Economics, Beijing Institute of Technology, Beijing 100081, China

\section{Introduction}

The Sendai Framework for Disaster Risk Reduction 2015-2030 prioritizes risk governance as a key factor for improving the capacity for disaster risk reduction. Disaster risk governance at the national, regional, and global levels is of great importance for an effective and efficient management of disaster risks (UNISDR 2015). Policies are a main instrument for governments to build a sustainable governance structure. Globally, current disaster risk governance policies result from long, evolutionary processes involving many rounds of policy development, and emergencies have been the primary impetus for the policy cycles (Henstra 2011). Scholars have increasingly turned their attention to historical patterns of policy change in disaster management, seeking to explain the dynamics of policy stability and change over time (Porfir'ev 1998; Britton 2007; Haddow et al. 2008).

China is a disaster-prone country, with more than $70 \%$ of its cities and $50 \%$ of its population located in areas that can be affected by geological, hydrometeorological, and other natural hazards (MCADR 2008). The frequency, complexity, severity, and extensiveness of natural hazards in China create a rare context for disaster occurrence globally (Li 2008). Historically, a major feature of China's disaster relief efforts has been effective organization by the 
government. From the granary system of the Sui and Tang Dynasties (AD581-907) to the disaster relief governance ${ }^{1}$ of the eighteenth century, the Chinese state played a key role in disaster relief efforts (Will 1990). Since the founding of the People's Republic of China (PRC) in 1949, many disasters have not only hit China with huge impacts, with significant casualties and economic losses, but also provided the government with opportunities for policy learning, which have resulted in a shift from its previous passive response to disaster risk management and governance (Zhang 2015). Through a bibliometric analysis of documents on disaster management policies, this article analyzes the dynamic changes and trends of disaster response policies since 1949. It aims to outline a holistic view of the historical evolution of the policy system so as to facilitate the understanding of the evolving process of the disaster management system in China and how disaster policy changes occurred, and to explore future pathways of transformation, guided by the Sendai Framework and the Sustainable Development Goals.

Before scholars in the bibliometric field turned their attention to policy studies, bibliometric study was widely used in library and information science, especially for analyzing co-citation relationships (Osareh 1996; Cronin 2001; Pagel and Hudetz 2011). Bibliometric analysis of documents on policies is instrumental to uncovering patterns and the trajectory of policy development, and has been widely used in the science policy field, such as the study of environmental change (Law et al. 1988), neuroscience (Gómez et al. 1990), public health (English and Pourbohloul 2017), and so forth. Derived from co-citation analysis that is commonly used for studies in information science, co-word analysis is also applied in policy studies (Coulter et al. 1998; Ding et al. 2001).

This study aimed to identify the trajectory and fundamental shifts of policies in the disaster domain in China. Given the limited space, this article only covers the time period from 1949 to 2016. It addresses the following three questions:

(1) Since the founding of the PRC in 1949, have there been distinct phases in the disaster management policy system?

(2) What were the policy priorities of disaster management in different phases?

\footnotetext{
${ }^{1}$ Disaster relief systems were an important part of the feudal political system in China. Throughout the course of the continuous fight against natural hazards and disasters, multiple disaster relief measures were gradually developed, amounting to the establishment of a policy framework that consisted of disaster reporting, investigation, tax exemption, and disaster relief during the Ming Dynasty. With further development during the Qing Dynasty, the policy framework was extended to include warehousing and river transport governance as part of a comprehensive policy system (Kang 2006).
}

(3) What were the changes to the government departments and institutions involved in the disaster management policy network and their interdepartmental relations?

\section{Patterns of Policy Change in Disaster Management in China}

Disasters are inherently social phenomena, with their roots embedded in social structures as they reflect the process of social changes (Tierney 2007). To a certain extent, a disaster is seen as a crisis with a devastating ending (Tierney 2007). Information asymmetry and urgent needs may trigger policymaking dilemmas comparing to the routine scenario. The top-down policy-making system may make it worse and this urges policymakers to reconsider the interactions between the central government, local governments, and the society while coping with disasters in China (Zhang and Zhang 2008). Hence, a disaster may also serve as an opportunity for structural changes: a danger, as a source for problems, could also become a window of opportunity that advances policy transformations (Kingdon 2003).

Traditional approaches to analyzing policy processes and policy change apply the advocacy coalition framework (ACF) (Sabatier 1987, 1988; Sabatier and Jenkins-Smith 1993), the punctuated-equilibrium theory (PET) (Jones et al. 1993), and the multiple streams approach (MS) (Kingdon 2003), among others. These theories, frameworks, and approaches aim to uncover the underlying generative causal processes that constitute the drivers of policy dynamics (change and stability). Unfortunately, these approaches only constitute the starting point for elaborating a more comprehensive theoretical synthesis because of the misspecification of microlevel processes, institutional constraints, and boundary relationships (RealDato 2009).

There is a growing recognition that disaster brings an opportunity to facilitate long-term economic, social, and physical developments (Berke et al. 1993). This raises great interest among scholars to look deeper into the questions about what kind of policy changes have been triggered by disasters and how they happened. Kingdon (2003) suggests that one way of analyzing policy change is to examine the role of policy entrepreneurs who may use any window of opportunity to force governments to address specific issues of interest to them. Policy issues or problems themselves do not automatically get on the government agenda unless they are taken up or given a push by relevant policy entrepreneurs (Kingdon 2003). This push may also emerge from a dramatic event—such as disasters 
or external shocks (Birkland 1997; Kingdon 2003; Lowry 2006) or "circumstantial reactors" (Elder and Cobb 1983) - as it opens these windows by providing an urgent, symbol-rich example of claimed policy failure that needs to be addressed immediately (May 1992; Birkland 2006).

With its recent history of rapid socioeconomic development, along with the onset of global climate change, China's disaster management policies have undergone major changes from 1949 to date (Zou and Yuan 2010; Zhang 2015). There is a daunting theoretical challenge on how to explore the trajectory of policy changes, the characteristics of different phases of change, and the drivers. Addressing how policies are made in China is difficult-it is very different from the Western context where mechanisms that form policies and political decision making could be captured by how issues get onto the agenda of governments. However, similar to the Western context, in China, a dramatic event itself is not enough to raise the issue to the policy agenda (Elder and Cobb 1983). Policy changes after "focusing events" also need to be accompanied by something else, such as the alignment of the political stream, the policy stream, and the promotion by policy entrepreneurs (Kingdon 2003).

Focusing events can drive governments to react to disasters because people tend to intuitively and normatively believe that big events "should" yield positive policy change to prevent a recurrence of the bad effects of the immediate events (Birkland and Warnement 2013a). It makes sense to assume that regardless of the political context of a country, "focusing events" are still a useful conceptual framework to expound paradigm shift and policy change. If a government fails to "learn the lessons" of focusing events, it will automatically become the prima facie evidence of dysfunctional governance (Birkland and Warnement 2013b), which leads to potential social instability. As suggested by Birkland and Warnement (2013a), it is important to consider how focusing events influence policy by looking at the level of the policy domain instead of staying at the level of individual events. This will enable us to understand long-term agenda and policy dynamics in a domain that is prone to focusing events.

Key decisions on policy shifts within the Chinese government were made through complex bargaining-coordinating processes that are often inaccessible to the academic community. Therefore, using focusing events as a guiding framework for examining changes in disaster management policies in the Chinese context is useful. Empirical study with the support of quantitative data from bibliometric analysis of policy documents should provide insights on not only the pattern of past policy change, but also possible pathways towards the transformation of disaster management and governance policies for a safer and sustainable future of the society.

\section{Methodology}

The data of policy documents were extracted from the PKULaw Database ${ }^{2}$ by our research team- "disaster" (Zaihai) was used as the keyword for the search in the database. More than ten-thousand policy documents from 1949 to 2016 at the state level that contain the word "disaster" have been retrieved (including those by the Central Committee of the Communist Party of China (CPC), the State Council and its direct affiliations, national bureaus, national associations, and national offices directly under the Central Committee of the CPC). Among these documents, 5472 were validated as related to natural hazard-induced disasters. Each of the selected policy documents includes keywords, ${ }^{3}$ policy-making departments, level of authority, regulatory category, year, and effectiveness status.

Using the method of bibliometric analysis on these policy documents, the trajectory and phases of evolution of China's disaster management system were mapped out through the social network analysis method, based on factors of policy priorities and interdepartmental cooperation network. Co-word analysis and cluster analysiscommonly used in mapping research topics or tracing patterns (Callon et al. 1991; Courtial 1994; Coulter et al. 1998; Ding et al. 2001; Huang et al. 2015)-were employed in this study.

(1) Keywords of high degree centrality in policy documents of different phases are identified and analyzed. Callon et al. (1986) define degree centrality as a measurement of one keyword's "co-appearance" with others. Specifically, degree centrality evaluates how many times one keyword is connected with others, which is to measure the frequency of the keyword's co-occurrence with others. For example, if keyword A and keyword B are mentioned together in five issued policy documents, then the degree centrality of either keyword A or keyword B simply becomes five. In order to accelerate the calculation of the co-occurrence of keywords, keywords of policy documents are placed into a matrix, then the generated co-word matrix is imported into Ucinet ${ }^{4}$ for matrix analysis to identify the keywords of highest degree centrality in a specific policy context during a particular period (De Bakker et al. 2005; Wagner and Leydesdorff 2005; Pilkington and Meredith 2009; Chang et al. 2010).

\footnotetext{
${ }^{2}$ PKULaw Database (http://www.pkulaw.cn) is the first and most influential Chinese legal document search system, recording all the policies, laws, and regulatory documents since 1949 .

${ }^{3}$ The keywords were initially selected in this study by the authors and double checked by focus group discussion with several experts from the public policy field and disaster management field.

${ }^{4}$ http://www.analytictech.com/.
} 
Betweenness centrality is another important type of centrality in social network analysis (SNA). Freeman (1977) defines betweenness centrality as a measurement that measures how many times a node in a network has to be passed by. In other words, betweenness centrality of node $\mathrm{X}$ can be interpreted as how many times node $\mathrm{X}$ becomes the pathway when other nodes connect with each other in the network. Cluster analysis derives from the concept of betweenness centrality for nodes and edges. Newman's (2004) algorithm is about calculating the betweenness centrality of pathways among all nodes in the network, and abandoning the one with the highest betweenness centrality. By repeating this process exhaustively, the program will identify the most influential node and its little "tails" formed into one cluster (subgroup) (Newman 2004). Therefore, Carrington et al. (2005) conclude that cluster analysis is to form the most connected nodes into one group, and remove nodes with little connection outside the subgroup. For instance, node A, node $\mathrm{B}$, and node $\mathrm{C}$ are connected with each other, but node $\mathrm{D}$ has no connection with any of them; then $\mathrm{A}, \mathrm{B}$, and $\mathrm{C}$ form a cluster without $\mathrm{D}$. Nodes that are more connected to one another have a higher possibility to stay in one subgroup (Himelboim et al. 2013). In NodeXL, ${ }^{5}$ different clusters (subgroups) are marked with different colors. The connotations of keywords are therefore explored through the cluster analysis (Smith et al. 2009; Shneiderman and Dunne 2012; Himelboim et al. 2013), whereas the shifts of policy priorities are observed through analyzing the changes in keywords of high degree centrality.

(2) Research on the interdepartmental cooperation relationship among policy-making departments during different phases is conducted, by using the same processes and algorithms as the ones used in co-word and cluster analyses. A matrix of government departments is generated based on cases of joint issuance of policy documents across departments, which is then imported into NodeXL for interdepartmental network and cluster analysis. Within the network, the lines connecting different government departments indicate previous cases of joint issuance of documents. The larger the size of a node, the more cases of previous joint issuance there have been (Bonsignore et al. 2009; Mohammad et al. 2009; De Liddo et al. 2011; Hansen et al. 2011), which highlights the significant role of that particular policy-making department in that field ${ }^{6}$ (Huang et al. 2015).

(3) The dynamics of the policy cooperation network of major disaster management departments are then

\footnotetext{
5 https://nodexl.codeplex.com/.

6 To control the number of nodes so as to generate a clear Node XL map, the threshold values of frequency are set at $2,4,5,6$, or 10 during the sorting of datasets.
}

examined. The main competent authority of natural hazardinduced disaster response is the Ministry of Civil Affairs (MCA), therefore MCA is treated as the central government department for analyzing changes of the cooperation network. The disaster-related policy documents released by the Ministry of Civil Affairs jointly with other departments can be used as the indicator to analyze MCA's collaboration with other policy-making departments. In the visualization of the network, the wider the connecting lines, the more policy documents the Ministry of Civil Affairs has issued together with the concerned policy-making department.

\section{Findings}

Figure 1 illustrates the annual number of disaster policies issued from 1949 to 2016, representing different growth trends in different phases. From 1949 to 1978, the number of disaster policies released each year remained steady, without significant changes. From 1979, the number of new disaster policies started to increase gradually. Starting from 2003, the number of disaster policies witnessed a period of rapid growth, which peaked in 2008-a year that recorded 660 issuances of disaster-related policies. After 2008, the annual number of new disaster-related policies started to decline, with occasional fluctuations. This phased development of new disaster policies is consistent with the findings of previous research. Based on these statistics, the development of China's disaster management system can be divided into four stages: Phase I lasted from 1949 to 1978, with the reform and opening-up of China as a turning point; Phase II extended from 1979 to 2003, ending with the severe acute respiratory syndrome (SARS) outbreak; Phase III covered the period between 2004 and 2008, marked at the end by the strike of the May 2008 Wenchuan Earthquake; Phase IV began in 2009 and extends to the present (Zhang 2015). The following policy bibliometric analysis is based on these four historical phases.

\subsection{Phase I, 1949-1978}

As indicated in Fig. 1, a relatively limited number of disaster-related policies was released between 1949 and 1978. The bibliometric analysis of disaster policy in this phase presents the keywords of high degree centrality listed in Table $1 .^{7}$ The cluster analysis of keywords (Fig. 2) demonstrates a complete food production-oriented

\footnotetext{
7 As the number of policy documents on natural hazard-induced disasters was very limited in the early years, but many policy documents were issued in later phases, different numbers of keywords of high degree centrality are identified and analyzed for different phases.
} 


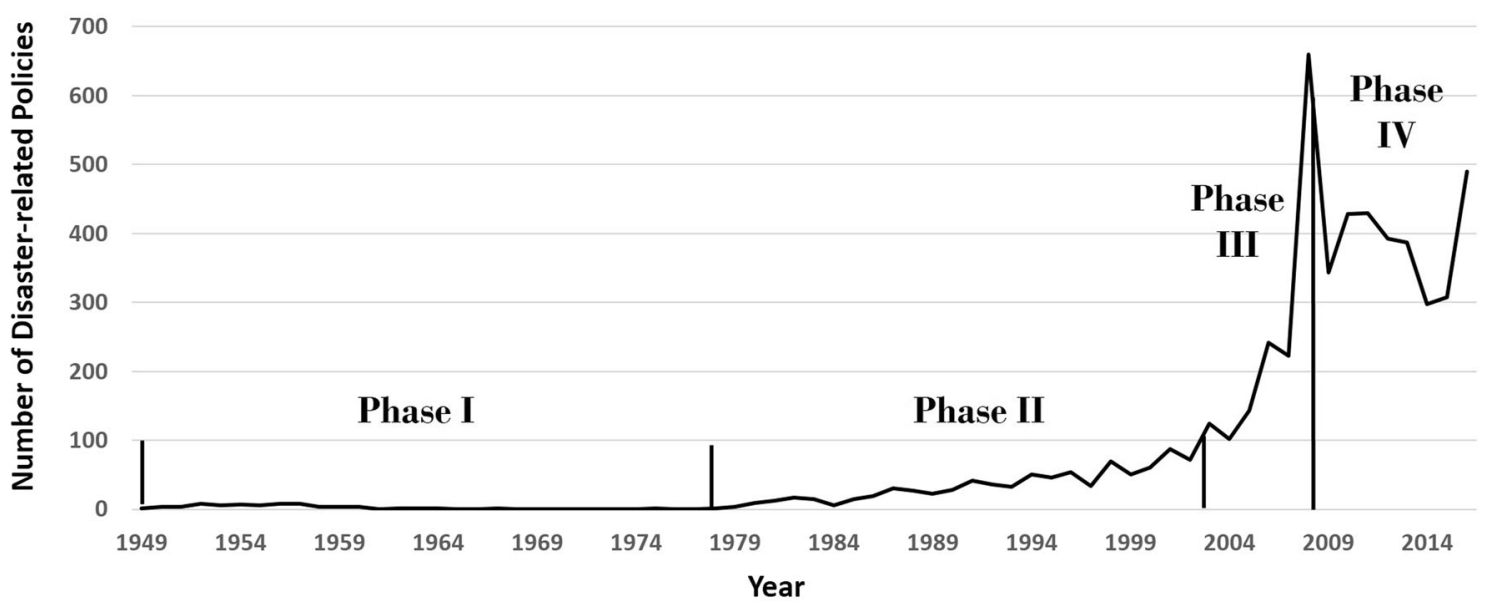

Fig. 1 Annual number of released disaster-related policies in China, 1949-2016

Table 1 Ranking of keywords of high degree centrality for Phase I (1949-1978) disaster policies in China

\begin{tabular}{llll}
\hline No. & Keywords & No. & Keywords \\
\hline 1 & Flood prevention & 7 & Rural area \\
2 & Drought control & 8 & Spring-time production \\
3 & General public & 9 & Food \\
4 & Centralized supply and marketing & 10 & Leadership \\
5 & Mutually beneficial policy & 11 & Agricultural production cooperative \\
6 & Agricultural cooperation & 12 & Mutual assistance and cooperation \\
\hline
\end{tabular}

Keywords in the table are listed in the order of degree centrality

Fig. 2 Co-word analysis and cluster analysis of Phase I (1949-1978) disaster policies in China

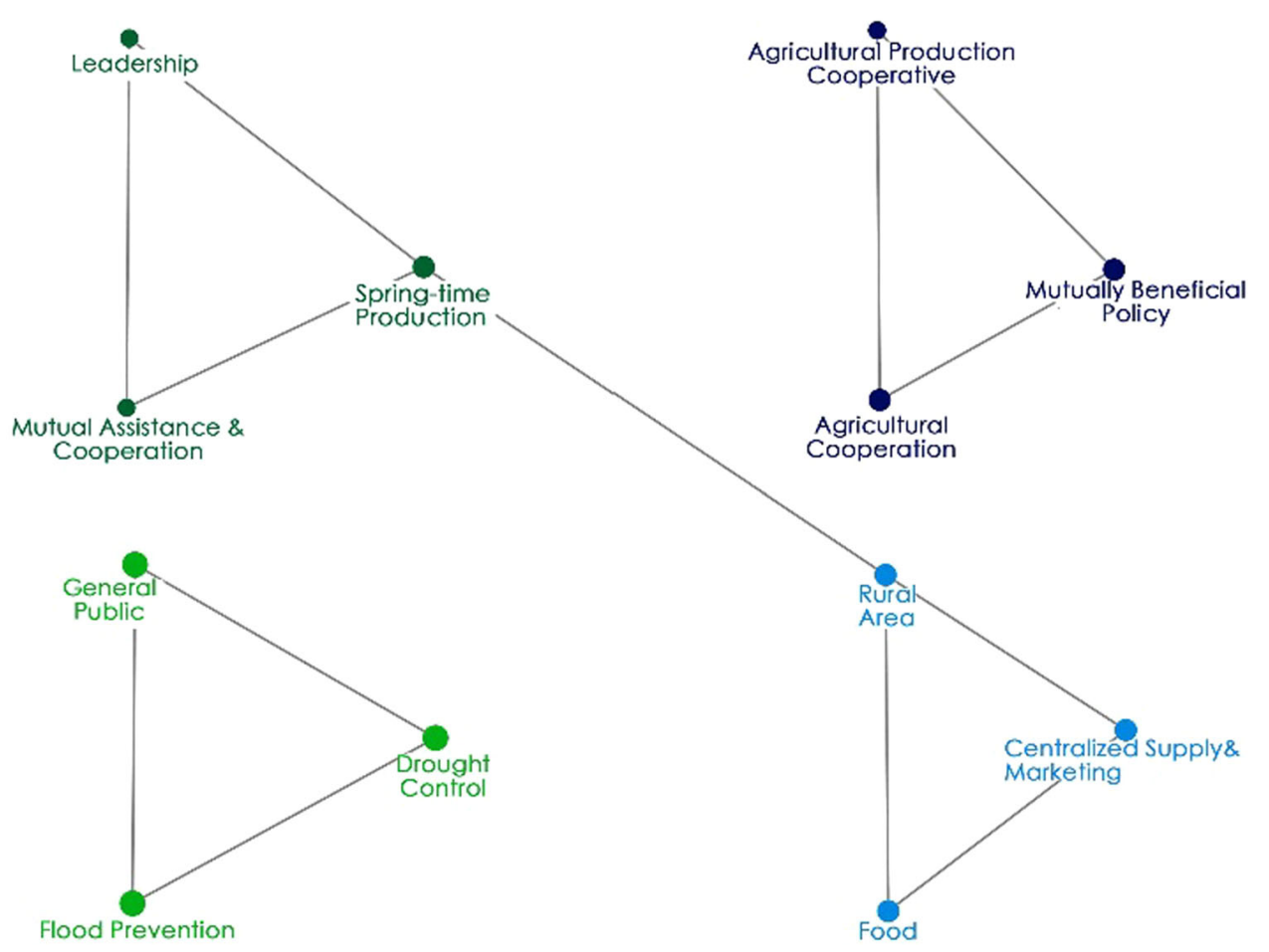




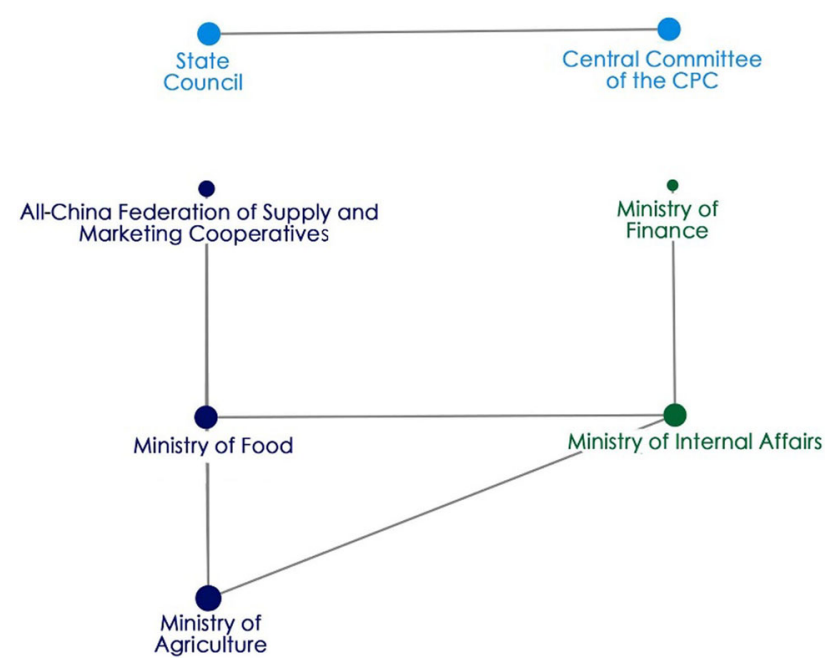

Fig. 3 Network of disaster policy-making departments of Phase I (1949-1978) in China. Ministry of Food was transformed into State Administration of Grain in 1999. Ministry of Internal Affairs was changed to Ministry of Civil Affairs in 1978

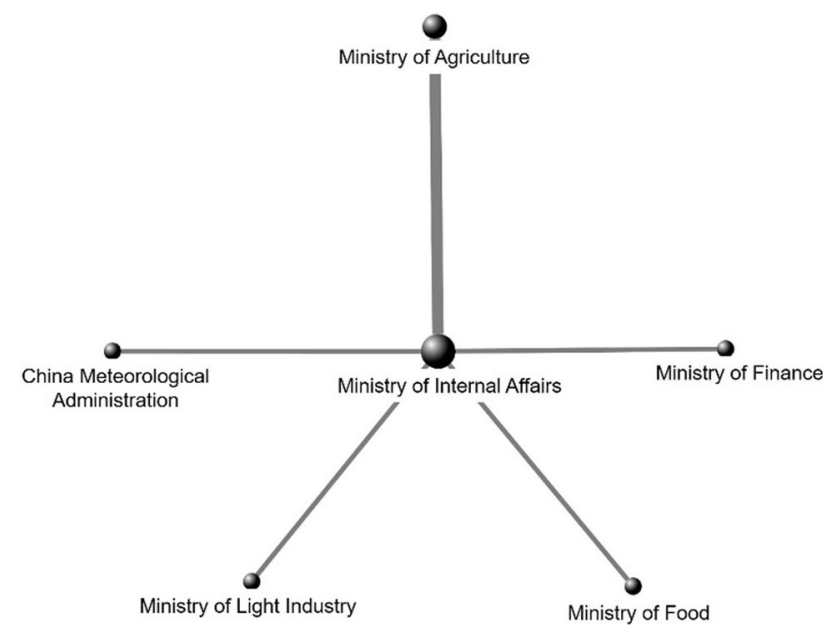

Fig. 4 Phase I (1949-1978) cooperative relationship analysis between the Ministry of Internal Affairs and other government departments in China. Ministry of Light Industry was dissolved in 1993

framework in Phase I that prioritizes agriculture, consisting of: (1) Production cooperation subgroup, which mainly focuses on means of production; (2) Spring-time production subgroup, which mainly focuses on the opportune time of production; (3) Drought control and flood prevention subgroup, which mainly focuses on human resource motivation and mobilization for disaster prevention and mitigation; and (4) Centralized supply and marketing subgroup, which mainly focuses on general management of food procurement and distribution.

Network analysis of the disaster policy-making departments (Fig. 3) shows that three major subgroups emerged among the policy-making departments during this period, with the first policy-making subgroup consisting of the Central Committee of the CPC and the State Council (Government Administration Council), the second policymaking subgroup centering around the Ministry of Agriculture, supplemented with the Ministry of Food and the All-China Federation of Supply and Marketing Cooperatives, and the third policy-making subgroup including the Ministry of Internal Affairs and the Ministry of Finance. In addition to the vital role of the Central Committee of the CPC and the State Council, the Ministry of Agriculture, Ministry of Internal Affairs, Ministry of Food, and Ministry of Finance are all central departments for disaster management.

On 27 February 1950, a leading disaster relief coordinating organization-the Central Disaster Relief Committee was officially established. A top-down mass mobilization approach became a signature path for the Chinese government to initiate disaster rescue and relief activities. At that time, Vice Premier Dong Biwu of the Government Administration Council directed the Committee, whereas the Ministry of Internal Affairs was entrusted with daily operations of the Committee. Responses to major disasters generally adopted the mechanism of full mobilization of all stakeholders. Seen from the results of cooperative relationship analysis between the Ministry of Internal Affairs-as one of the main competent authorities for disaster response during this phase-and other departments (Fig. 4), the Ministry of Internal Affairs' main policy collaborators were the Ministry of Agriculture, China Meteorological Administration, Ministry of Finance, Ministry of Light Industry, and Ministry of Food. Among these five departments, the Ministry of Agriculture had the closest ties with the Ministry of Internal Affairs, which is highly aligned with the analysis results of keywords of high degree centrality, indicating that the priority of the disaster management policies of this phase was protection of the safety of agricultural production.

\subsection{Phase II, 1979-2003}

As indicated by the ranking list of keywords of high degree centrality in Table 2, agriculture is the only keyword associated with the agricultural sector, despite of its high degree centrality. An increasing number of newly emerged keywords are associated with economic development, including industry, national economic planning, domestic commerce, along with keywords related to integrated social development, including culture, education, science and technology, and health.

A further cluster analysis of the keyword network (Fig. 5) reveals the four keyword-clusters: (1) Economic development subgroup; (2) Diversified agricultural subgroup; (3) Disaster response subgroup; and (4) Financial 
Table 2 Ranking of keywords of high degree centrality for Phase II (1979-2003) disaster policies in China

\begin{tabular}{llll}
\hline No. & Keywords & No. & Keywords \\
\hline 1 & Agriculture & 16 & Infrastructure construction \\
2 & Culture & 17 & Management \\
3 & Industry & 18 & Rigorous implementation \\
4 & Education & 19 & Urban landscape and features preservation \\
5 & Science and technology & 20 & Financial management \\
6 & Livelihood & 21 & Function disposition \\
7 & Population & 22 & Ecological environment \\
8 & National economic plan & 23 & Legal responsibility \\
9 & Execution result & 24 & Environment protection \\
10 & Transportation & 25 & Railway \\
11 & Post and telecommunication & 26 & Fixed asset \\
12 & Sports & 27 & General guidance \\
13 & Foreign trade and tourism & 28 & Cost control \\
14 & Domestic commerce & 29 & Supervision and inspection \\
15 & Health & 30 & Usage \\
\hline
\end{tabular}

Keywords in the table are listed in the order of degree centrality

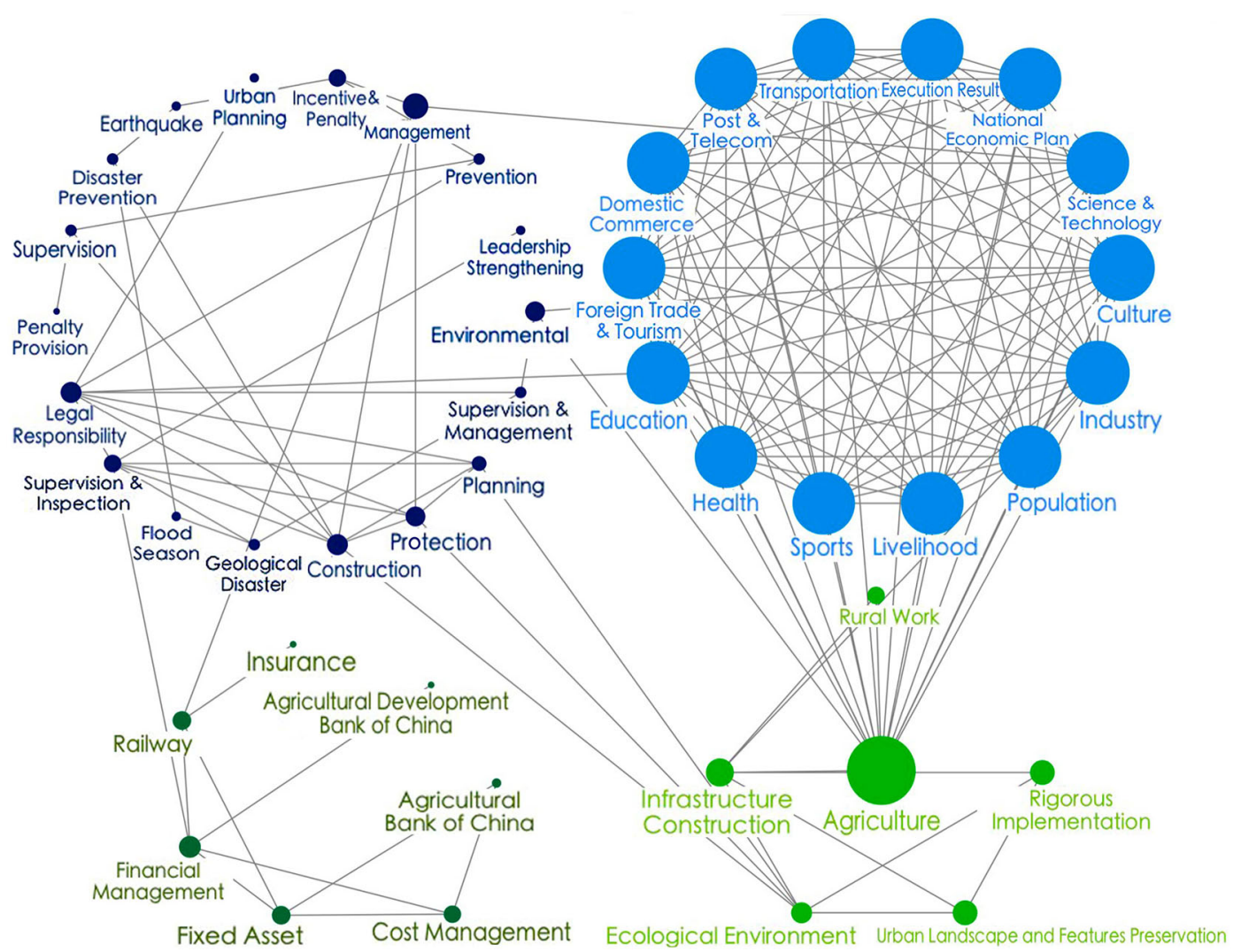

Fig. 5 Co-word analysis and cluster analysis of Phase II (1979-2003) disaster policies in China

management subgroup. By comparison, the disaster response subgroup had a smaller average degree centrality, including keywords such as "geological disaster", "earthquake", "supervision and management", and "legal responsibility", as reflected in the policy document $\mathrm{Na}$ tional Plan for Geological Disaster Prevention and 


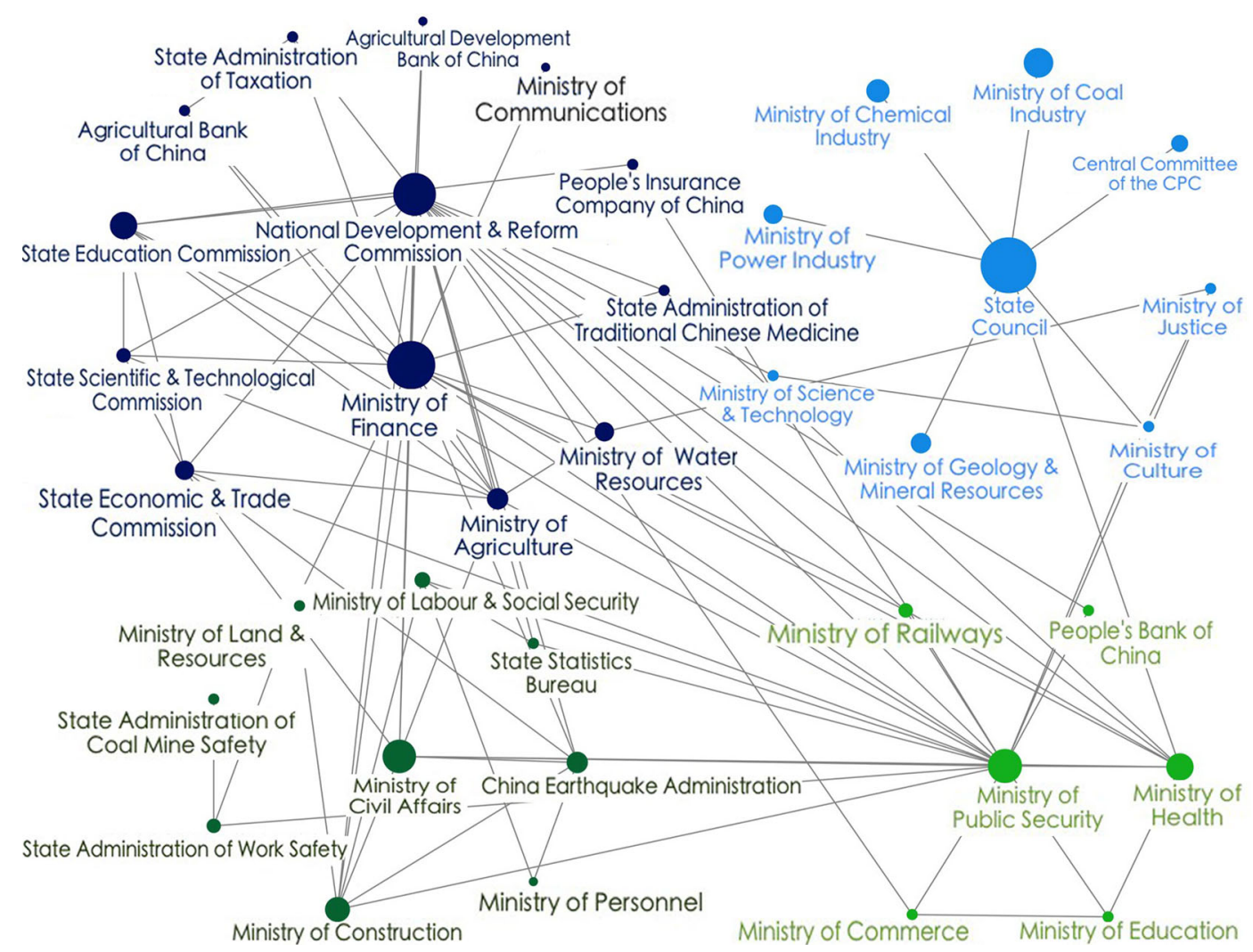

Fig. 6 Network of disaster policy-making departments of Phase II (1979-2003) in China. National Development and Reform Commission was previously called State Planning Commission and State Development Planning Commission. State Education Commission was transformed into Ministry of Education in 1998. State Scientific and Technological Commission was turned into Ministry of Science and Technology in 1998. State Economic and Trade Commission was dissolved in 1998. Ministry of Communications was merged into Ministry of Transport in 2008. Ministry of Human Resource and Social Security was established in 2008, and was called Ministry of Labour, Ministry of Personnel, and State Bureau of Labour before.

Control. ${ }^{8}$ Seen from both the cluster analysis and the table of degree centrality, the disaster relief-related keywords did not emerge as prominent keywords during this phase, which also reflects the continuation of the Chinese government's approach of mobilization-based disaster relief efforts.

Network analysis of the disaster policy-making departments (Fig. 6) shows that four important policy-making subgroups are shaped among the policy-making departments during this period: (1) Policy-making subgroup centering around the Central Committee of the CPC and the State Council, with the State Council taking on more prominent administrative functions in the field; (2) Policy-

\footnotetext{
${ }^{8}$ http://www.pkulaw.cn/fulltext_form.aspx?Db=chl\&Gid=39376\&ke yword=\%e5\%9c\%b0\%e8\%b4\%a8\%e7\%81\%be\%e5\%ae\%b3\%e9\% $98 \%$ b2\%e6\%b2\%bb\%e5\%b7\%a5\%e4\%bd\%9c\%e8\%a7\%84\%e5\% $88 \% 92 \%$ e $7 \%$ ba\%b2\%e8\%a6\%81\&EncodingName $=\&$ Search_Mode $=$ accurate $\&$ Search_IsTitle $=0$ (in Chinese).
}

Ministry of Construction was transformed into Ministry of Housing and Urban-Rural Development in 2008. Ministry of Railway was divided into Ministry of Transport and National Railway Administration in 2013. Ministry of Commerce was dissolved in 1993 and reestablished in 2003, containing Ministry of Foreign Trade and Economic Cooperation (1993-2003) and its predecessor Ministry of Foreign Economic Relations and Trade (1982-1993). National Earthquake Bureau was transformed to China Earthquake Administration in 1998. State Bureau of Work Safety was transformed into State Administration of Work Safety in 2003

making subgroup centering around both the National Development and Reform Commission and Ministry of Finance, supplemented with departments such as the Ministry of Water Resources, State Education Commission, and State Economic and Trade Commission; (3) Policy-making subgroup centering around the Ministry of Civil Affairs, supported by multi-departmental coordination that involves the China Earthquake Administration and Ministry of Construction; and (4) Policy-making subgroup centering around the Ministry of Public Security, supplemented with multiple departments including the Ministry of Health.

Based on the results of the cooperative relationship analysis between the Ministry of Civil Affairs-as one of the main competent authorities for disaster response during this phase-and other departments (Fig. 7), an additional eight departments are included into the system alongside the departments listed in Phase I. It is a manifestation of the 
Fig. 7 Phase II (1979-2003) cooperative relationship analysis between the Ministry of Civil Affairs and other government departments in China. China Commission for International Disaster Reduction changed its name to China National Commission for Disaster Reduction in 2005. State Council Leading Group for the Economic Development in Poverty-stricken Areas changed its name to State Council Leading Group Office of Poverty Alleviation and Development in 1993

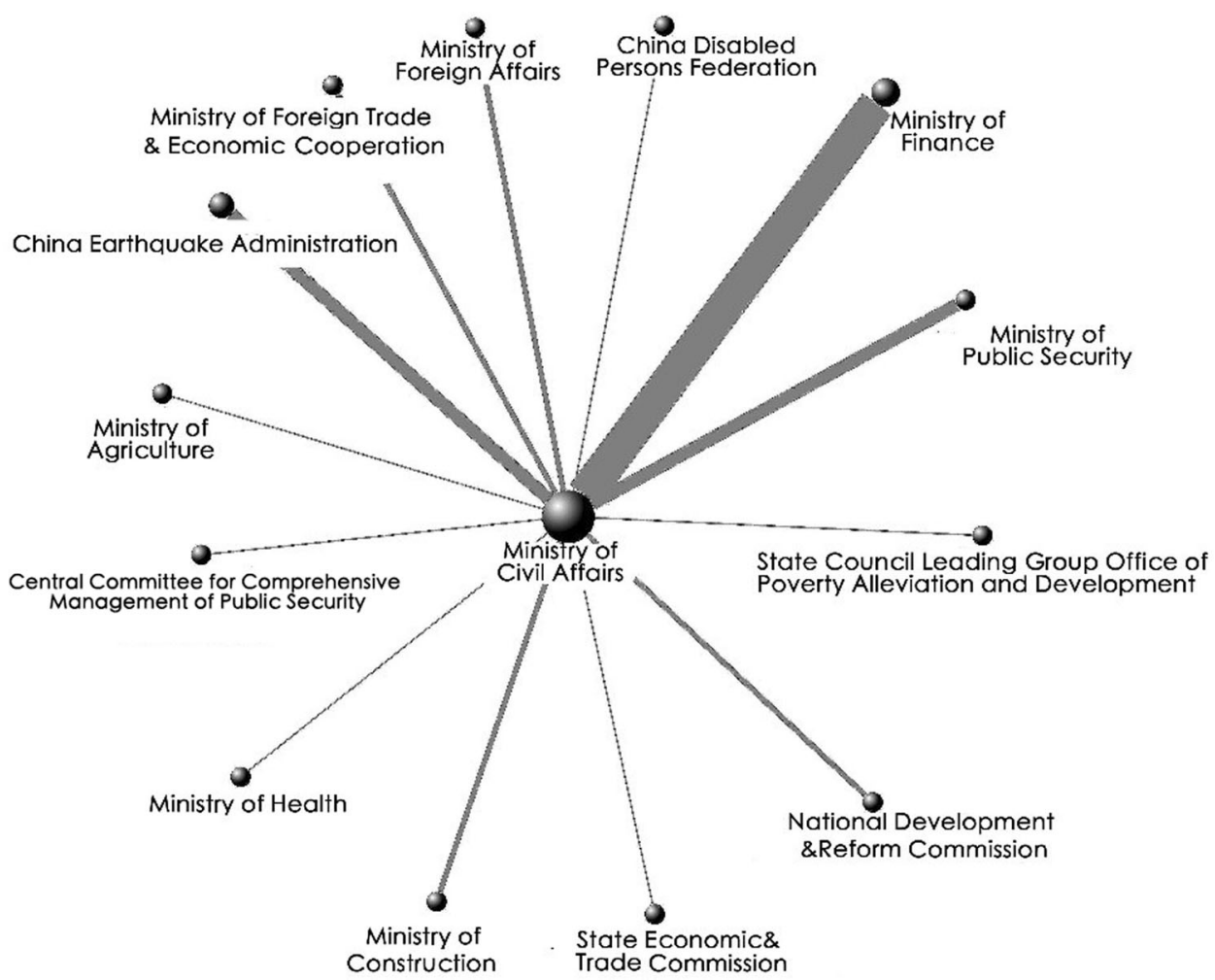

Table 3 Ranking of keywords of high degree centrality for Phase III (2004-2008) disaster policies in China

\begin{tabular}{llll}
\hline No. & Keywords & No. & Keywords \\
\hline 1 & Environmental protection & 16 & Comprehensive agricultural development \\
2 & Culture & 17 & Natural disaster damage \\
3 & Science, technology and education & 18 & Geological disaster \\
4 & Industry and construction & 19 & City scale \\
5 & Health and sports & 20 & Urban-rural coordinated development \\
6 & Transportation, post and telecommunication & 21 & Human settlement environment \\
7 & Domestic trade & 22 & Safe production \\
8 & National economy and social development & 23 & Emergency plan \\
9 & Comprehensiveness & 24 & Prevention and control \\
10 & Population and livelihood & 25 & Risk assessment \\
11 & Agriculture & 26 & Monitoring and early warning \\
12 & Outbound economy & 27 & Three Gorges Reservoir Region \\
13 & Fixed asset investment & 28 & Disaster prevention and mitigation \\
14 & Finance and insurance & 29 & Forestry technology \\
15 & Restoration project & 30 & Emergency management \\
\hline
\end{tabular}

Keywords in the table are listed in the order of degree centrality

gradual institutionalization of national procedures, with disaster management becoming an increasingly important element of national governance. Multiple policy documents demonstrated the government's renewed awareness of and commitment to preparing for and providing relief to natural hazard-induced disasters, including the Minutes of
Earthquake Disaster Countermeasures Symposium ${ }^{9}$ and the Agreement on Strengthened Interdepartmental

\footnotetext{
9 http://www.pkulaw.cn/fulltext_form.aspx?Db=chl\&Gid=25154\&ke yword=\%e3\%80\%8a\%e5\%9c\%b0\%e9\%9c\%87\%e6\%95\%91\%e7\% $81 \%$ be $\%$ e $5 \%$ af\%b9\%e7\%ad\%96\% $7 \%$ a0\%94\% $7 \%$ a9\%b6\%e5\%ba\% a7\%e8\%b0\%88\%e4\%bc\%9a\%e7\%ba\%aa\%e8\%a6\%81\%e3\%80\%8b\&
} 


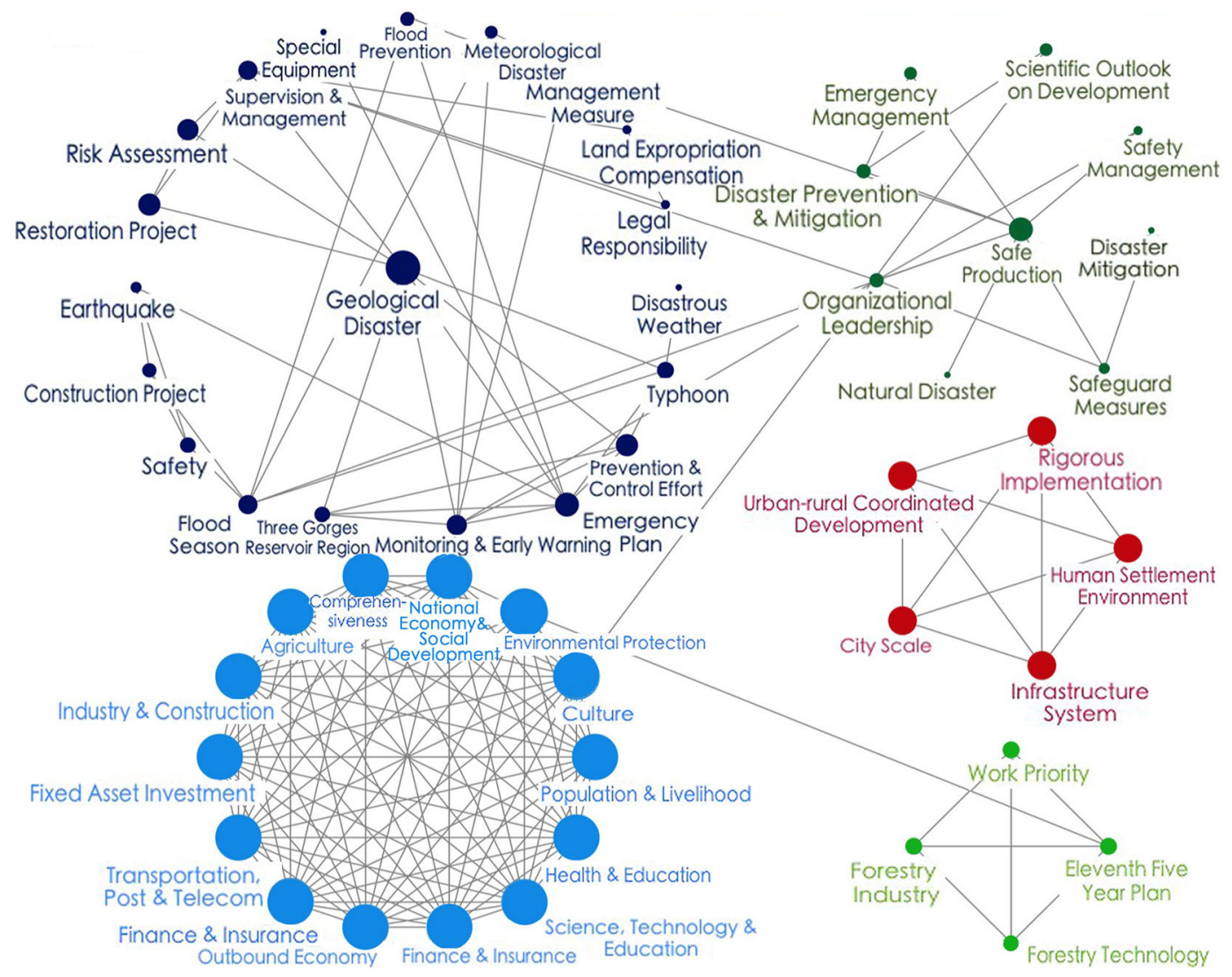

Fig. 8 Co-word analysis and cluster analysis of Phase III (2004-2008) disaster policies in China

Cooperation between the Ministry of Civil Affairs and China Earthquake Administration ${ }^{10}$ jointly released by the two departments, as well as the Opinions on Strengthening Earthquake Preparedness in Key Areas for Earthquake Surveillance ${ }^{11}$ jointly released by the Ministry of Civil Affairs, Ministry of Construction, and China Earthquake Administration. Among the collaborations, the Ministry of Civil Affairs had the closest cooperative relationship with

\section{Footnote 9 continued}

EncodingName $=\&$ Search_Mode $=$ accurate $\&$ Search_IsTitle $=0 \quad$ (in Chinese).

${ }^{10}$ http://www.pkulaw.cn/fulltext_form.aspx?Db=chl\&Gid=25166\& keyword=\%e3\%80\%8a\%e6\%b0\%91\%e6\%94\%bf\%e9\%83\%a8\% e5\%92\%8c\%e5\%9b\%bd\%e5\%ae\%b6\%e5\%9c\%b0\%e9\%9c\%87\% e $5 \%$ b1\%80\% e5\%85\%b3\%e4\%ba\%8e\%e5\%8a\%a0\%e5\%bc\%ba\% e $9 \% 83 \%$ a8\% e9\%97\%a8\%e4\%b9\%8b\%e9\%97\%b4\%e5\%90\% $88 \%$ e $4 \%$ bd $\% 9$ c \&EncodingName $=\&$ Search_Mode $=$ accurate $\&$ Search_IsTitle $=0$ (in Chinese).

${ }^{11} \mathrm{http}: / /$ www.pkulaw.cn/fulltext_form.aspx?Db=chl\&Gid=25165\&ke yword $=\%$ e $3 \% 80 \% 8 \mathrm{a} \%$ e $5 \% 85 \%$ b3\% e $4 \%$ ba $\% 8 \mathrm{e} \%$ e $5 \% 8 \mathrm{a} \% \mathrm{a} 0 \%$ e $5 \%$ bc\%ba\%e5\%9c\%b0\%e9\%9c\%87\%e9\%87\%8d\%e7\%82\%b9\%e7\% $9 \mathrm{~b} \% 91 \%$ e $8 \%$ a7\% $86 \%$ e5\%8c\%ba\%e7\%9a\%84\%e5\%9c\%b0\%e9\% 9c\%87\%e9\%98\%b2\%e7\%81\%be\%e5\%b7\%a5\%e4\%bd\%9c\%e7\% $9 \mathrm{a} \% 84 \&$ EncodingName $=\&$ Search $\_$Mode $=$accurate $\&$ Search $\_$IsTi tle $=0$ (in Chinese) the Ministry of Finance, resulting in joint release of policy documents on disaster prevention, reduction, relief, and poverty alleviation, such as the Management Measures on Central Reserve of Disaster Relief Materials. ${ }^{12}$ The focus of these policies is consistent with the economic development-centered national strategy during this phase.

\subsection{Phase III, 2004-2008}

As shown in Fig. 1, the number of disaster response policies starts to surge after 2003 , to a great extent due to the systemic efforts of the central government to reflect on lessons learned and build a national management system in the wake of the 2003 SARS outbreak. Many scholars also consider the year 2003 as a significant turning point that inherits the past and ushers in the future (Zhang 2015). Table 3 shows that keywords of high degree centrality such

\footnotetext{
$12 \mathrm{http} / / /$ www.pkulaw.cn/fulltext_form.aspx?Db=chl\&Gid=49604\&ke yword=\%e3\% $80 \% 8$ a $\%$ e $4 \%$ b8 $\%$ ad\% e $5 \%$ a $4 \%$ ae $\%$ e $7 \%$ ba $\%$ a $7 \%$ e6\% 95\%91\% e7\%81\%be\%e5\%82\%a8\% $5 \%$ a $4 \% 87 \%$ e7\% $89 \%$ a $9 \%$ e $8 \%$ b5\%84\%e7\%ae\%a1\%e7\%90\%86\%e 5\%8a\%9e\%e6\%b3\%95\%e3\% $80 \% 8$ b \&EncodingName $=\&$ Search_Mode $=$ accurate $\&$ Search_IsTi tle $=0$ (in Chinese).
} 
Fig. 9 Network of disaster policy-making departments of Phase III (2004-2008) in China

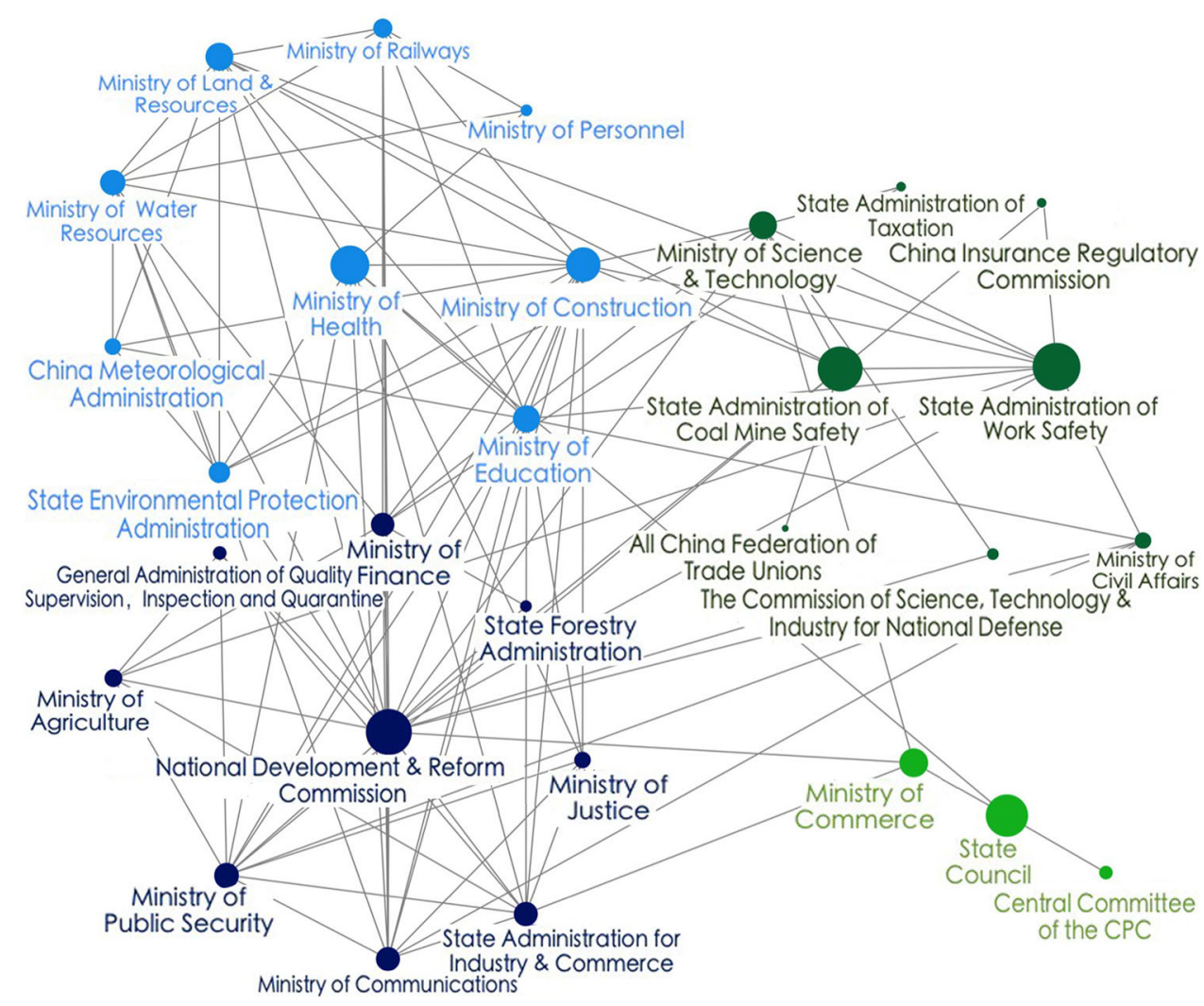

continued presence of urban, infrastructure, and agriculture subjects, as well as more prominent and specialized subgroups on geological disaster and safety in production. The geological disaster subgroup highlights risk assessment and protection measures in the wake of disasters, with a greater emphasis on day-to-day supervision and management. The emergence of keywords such as "emergency management" and "disaster prevention and mitigation" marks the establishment of a systematic disaster management system. However, due to top designs, the State Council Emergency Office and the emergency offices at different levels of local government are still internal departments, which are not formed into an independent and outstanding subgroup. It is noteworthy that forest fire prevention and its related keywords constitute a forestry subgroup. Meanwhile, the human settlement environment and urban-rural coordinated development also develop into a notable subgroup.

Based on the network analysis of the disaster policymaking departments (Fig. 9), four key policy subgroups of departments came into being: (1) Policy-making subgroup centering around the National Development and Reform Commission, with the Ministry of Finance, Ministry of Public Security, and State Administration for Industry and Commerce playing a leading role; (2) Policy-making subgroup centering around both the State Administration of Work Safety and State Administration of Coal Mine Safety, supplemented by the Ministry of Science and 
Table 4 Ranking of keywords of high degree centrality for Phase IV (2009-present) disaster policies in China

\begin{tabular}{llll}
\hline No. & Keywords & No. & Keywords \\
\hline 1 & Geological disaster & 16 & Flood season \\
2 & Human settlement environment & 17 & Disaster prevention and mitigation \\
3 & Rigorous implementation & 18 & Earthquake response and relief \\
4 & City scale & 19 & Search for potential hazards \\
5 & Infrastructure & 20 & Safeguard measures \\
6 & Resource-efficient and environment-friendly city & 21 & Post-disaster reconstruction \\
7 & Historic, cultural, landscape and feature conservation & 22 & Monitoring and early warning \\
8 & Urban-rural coordinated development & 23 & Supervision and inspection \\
9 & Risk assessment & 24 & Mass monitoring and disaster prevention \\
10 & Restoration project & 25 & Meteorological disaster \\
11 & Official approval and reply & 26 & Earthquake prevention and disaster mitigation \\
12 & Earthquake & 27 & Emergency duty \\
13 & Commercial insurance & 28 & Legal responsibility \\
14 & Agriculture & 29 & Wenchuan earthquake \\
15 & Safe production & 30 & Frozen rain and snow disaster \\
\hline
\end{tabular}

Keywords in the table are listed in the order of degree centrality

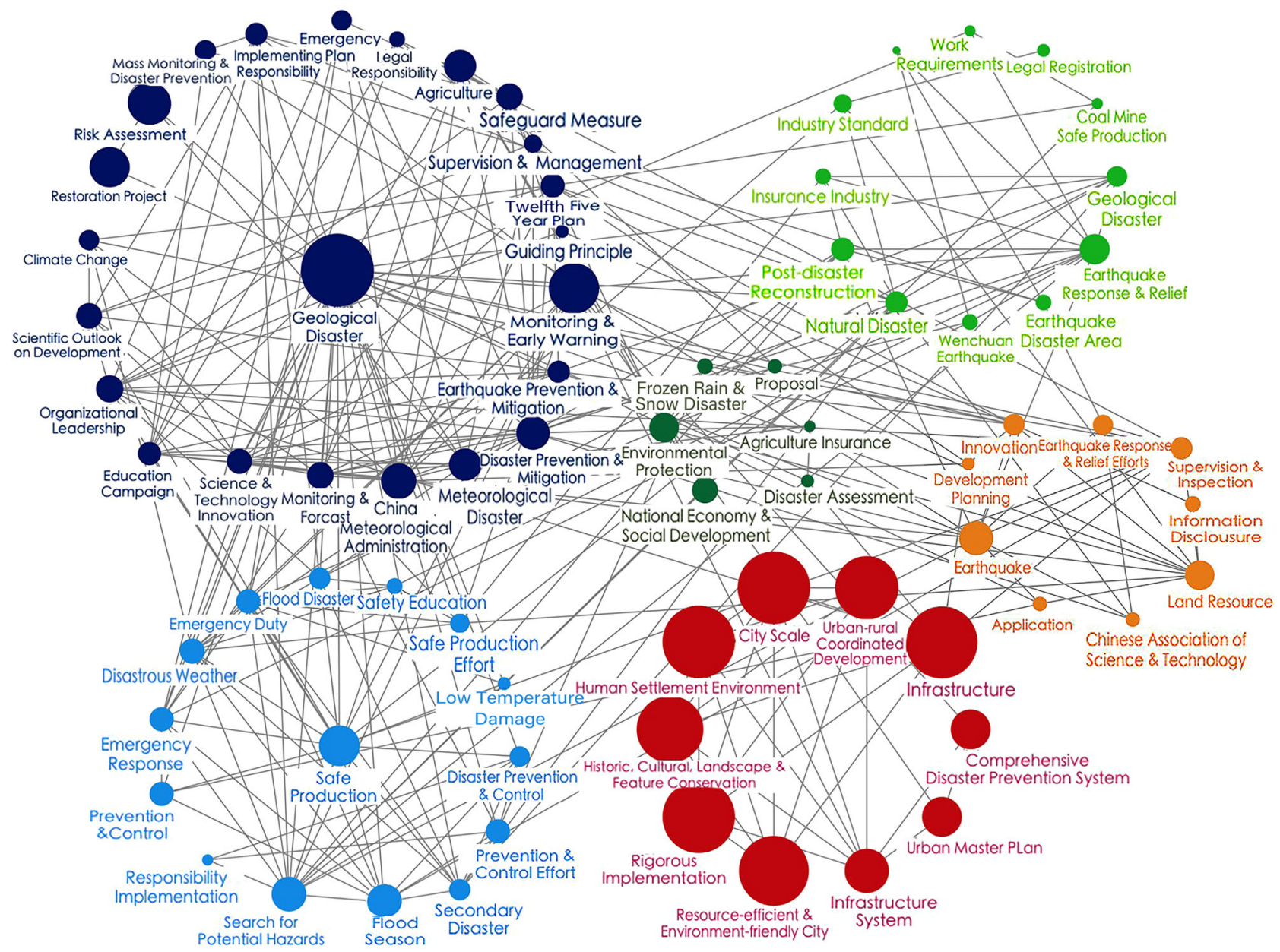

Fig. 11 Co-word analysis and cluster analysis of Phase IV (2009-present) disaster policies in China 


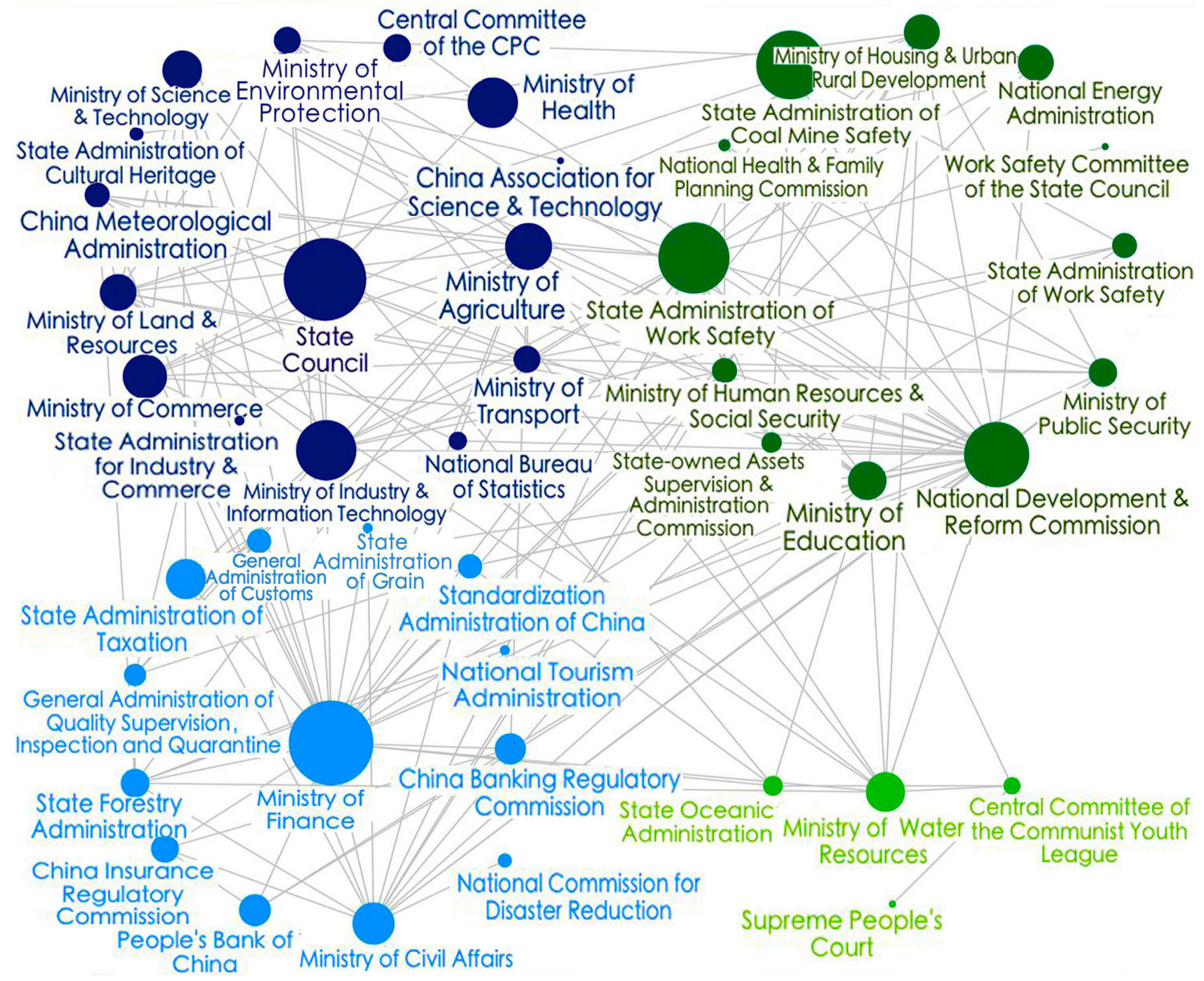

Fig. 12 Network of disaster policy-making departments of Phase IV (2009-present) in China

Technology and Ministry of Civil Affairs, in which case they provide policy guidance and supervision to the coal mining industry and other related industries on avoiding secondary disasters triggered by natural hazard-induced disasters; (3) Policy-making subgroup centering around the State Council and Central Committee of the CPC as a major subgroup for policy making; and (4) It is worth noting that the Ministry of Health for the first time became the center of a policy subgroup, coordinating with multiple departments including the Ministry of Education, which also reflects the general context and priorities of disaster response.

As shown by the cooperative relationship between the Ministry of Civil Affairs and other departments (Fig. 10), the National Commission for Disaster Reduction and National Development and Reform Commission were newly included departments, and the latter had the closest cooperative relationship with the Ministry of Civil Affairs.
This is reflected in the joint release of the Eleventh Five Year Plan for Civil Affairs Development, ${ }^{13}$ in which detailed planning for emergency response and relief for disaster victims are laid out at the national level, with clear indication of the increasingly pressing tasks of strengthening disaster prevention, mitigation and relief, improving social emergency management system, and ensuring better public safety, given the frequent strikes of natural hazardinduced disasters and emergencies.

\footnotetext{
13 http://www.pkulaw.cn/fulltext_form.aspx?Db=chl\&Gid=82696\& keyword=\%e3\%80\%8a\%e6\%b0\%91\%e6\%94\%bf\%e4\%ba\% $8 \mathrm{~b} \%$ e4\%b8\%9a\%e5\%8f\%91\%e5\%b1\%95\%e7\%ac\%ac\%e5\%8d\%81\%e4\% b8\%80\% e4\%b8\%aa\%e4\%ba\%94\%e5\%b9\%b4\%e8\%a7\%84\%e5\%88\% $92 \%$ e3\%80\%8b\&EncodingName $=\&$ Search $\_$Mode $=$accurate $\&$ Search IsTitle $=0$ (in Chinese).
} 


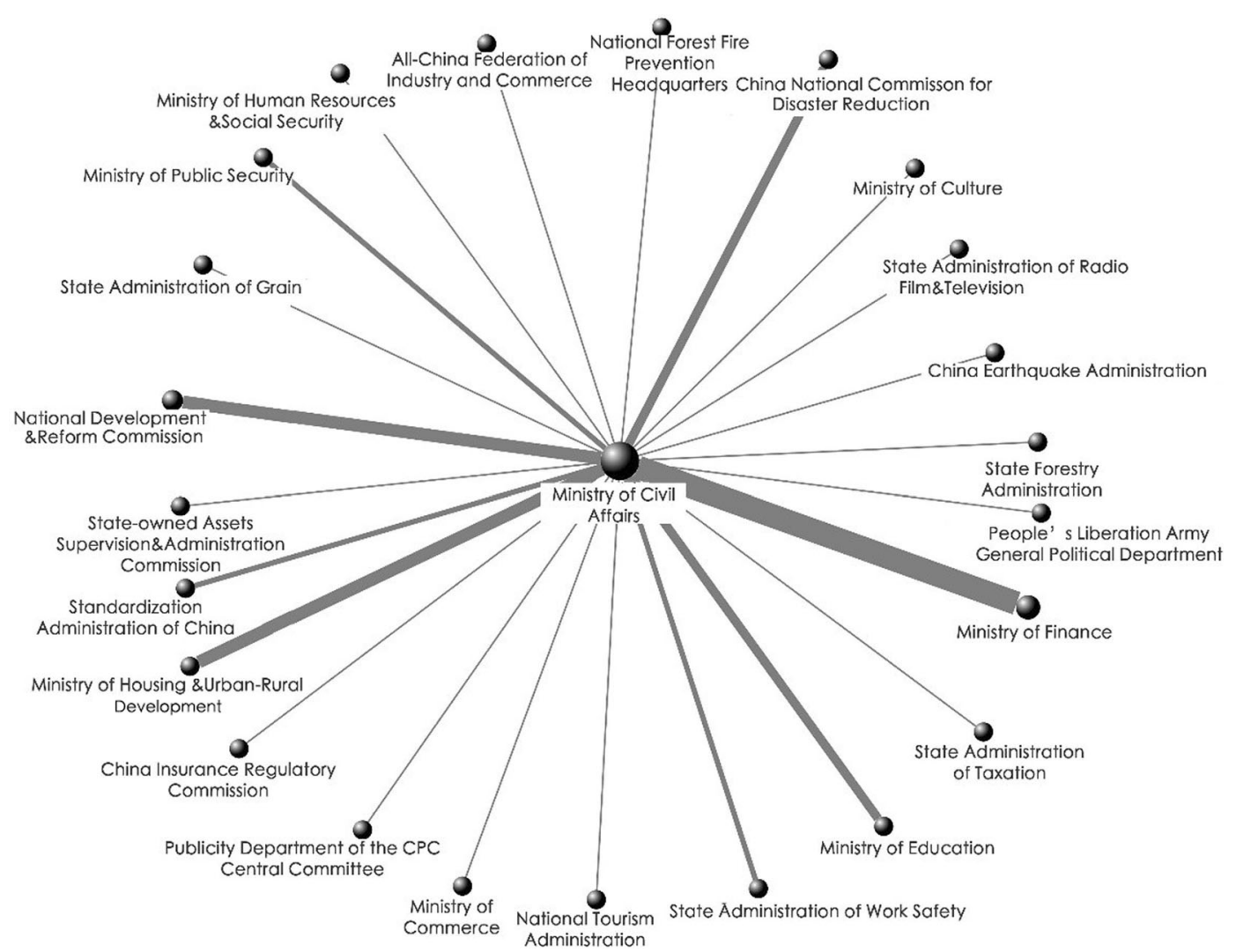

Fig. 13 Phase IV (2009-present) cooperative relationship analysis between the Ministry of Civil Affairs and other government departments in China. State Administration of Radio Film and

\subsection{Phase IV, 2009-Present}

According to Fig. 1, the number of disaster response policies started to decline after 2009, with occasional fluctuations. As Table 4 shows, in addition to keywords such as "geological disaster", "earthquake", and "disaster prevention and mitigation", a number of new keywords represent the highest degree centrality, including "human settlement environment", "city scale", and "urban-rural coordinated development." At the same time, keywords like "commercial insurance" and "legal responsibility" also become part of the list, marking the emergence of a law-based multi-department disaster management landscape. A closer observation of the keyword network from the cluster analysis (Fig. 11) reveals that the earthquakecentered policy subgroup became a policy hot topic after the Wenchuan Earthquake. The geological disaster subgroup continues to be a hotspot, with a focus on risk assessment and restoration project, as well as a greater emphasis on routine search for potential hazards and emergency duty assignments. The keywords such as "disaster prevention and mitigation", "post-disaster reconstruction", and "monitoring and early warning" reveal important policy hotspots. The subgroup with economic
Television was merged into State Administration of Press, Publication, Radio, Film and Television in 2013

characteristics is replaced by diversified subgroups, including the continued subjects of urban development, human settlement environment, and infrastructure. The impact of the Wenchuan Earthquake and the frozen rain and snow disasters continued to grow, leading to the formation of their corresponding policy subgroup.

Based on the network analysis of the disaster policymaking departments in Fig. 12, three key policy-making subgroups of departments were formed: (1) the subgroup centering around the State Council, continued from the previous phase; (2) the newly integrated policy-making subgroup centering around the Ministry of Civil Affairs and the Ministry of Finance; and (3) the policy-making subgroup centering around the National Development and Reform Commission and State Administration of Work Safety. This signifies that disaster management has become a regular function of national institutions, with the State Council, National Development and Reform Commission, and Ministry of Finance sitting at the center of the policy subgroups.

According to Fig. 13, the Ministry of Civil Affairs witnessed a remarkable increase of synergies achieved with other ministries, including not only specialized response agencies but also comprehensive management 
departments, such as the newly added departments of the State Administration of Radio, Film and Television, National Forest Fire Prevention Headquarters, Ministry of Human Resources and Social Security, People's Liberation Army General Political Department, All-China Federation of Industry, and Ministry of Housing and Urban-Rural Development. This indicates strong support provided by the National Development and Reform Commission and Ministry of Finance during this phase, with the latter having the closest collaborations with the Ministry of Civil Affairs. For instance, the Ministry of Civil Affairs and Ministry of Finance jointly released the Circular on the Implementation of "Provisional Measures on Social Relief", 14 which further highlighted the disaster victim relief system and strengthened social participation. Additionally, the China National Commission for Disaster Reduction further played its coordinating role by working concertedly with the Ministry of Civil Affairs on releasing documents for important tasks, such as demonstration communities for comprehensive disaster reduction and the statistical system for major natural disaster loss assessment.

\section{Discussion}

Based on the statistical findings, this section explores and analyzes the characteristics and underlying pattern of the evolving disaster management policies in China.

\subsection{Phase I (1949-1978): Focusing on Agriculture}

The analytical result shows a high correlation between agricultural production and disaster policy during this phase, which is closely related to the objective factors in China then, including politics, economy, and natural disaster. In 1949, when the People's Republic of China was just established, the infrastructure and economic foundations were relatively weak and therefore the national economy relied much on the stable development of agriculture. Agricultural vulnerability would jeopardize national stability. Frequent natural hazard-induced disasters posed a prominent threat to agriculture, the economic pillar at the time, and the safety of the Chinese people, forcing the government to put the focus of disaster policy and management on agricultural production. In 1949, the central government issued the Instructions of the State Council on Production-Oriented Disaster Reduction (MIA 1949), and in January 1950, the central government issued

\footnotetext{
14 http://www.pkulaw.cn/fulltext_form.aspx?Db=chl\&Gid=229750\& keyword=\% e3\%80\%8a\%e7\%a4\%be $\%$ e4\%bc\%9a\%e6\%95\%91\% $5 \%$ 8a\%a9\%e6\%9a\%82\%e8\%a1\%8c\%e5\%8a\%9e\%e6\% b3\%95\% e3\% $80 \% 8 \mathrm{~b} \&$ EncodingName $=\&$ Search_Mode $=$ accurate $\&$ Search_IsTitle $=0$ (in Chinese).
}

the Supplementary Instructions on Production-Oriented Disaster Reduction, which specified clearly that "disaster management, as an existential issue for millions of people and an issue of great importance to the stability of the new democracy regime in afflicted areas, was one priority in the Great Production Campaign in the next year and the development of the newly founded People's Republic of China" (MIA 1950, p. 1). It means that the resolution of problems related to regime satiability and subsistence was prioritized. Although China was ravaged by a series of major disasters in this phase-such as the Great Famine (1959-1961), the Great Tangshan Earthquake in 1976, and the floods in August 1975-disaster management was not taken seriously at the institutional level because the ideology "putting politics in command" remained predominant. Public awareness of disaster mitigation was weak, with some people holding the view of "Man can conquer nature." In the midst of an upheaval, "the national politics had no ability to deal with these issues" (Zhang 2003, p. 21).

\subsection{Phase II (1979-2003): Taking Economic Development as the Priority}

Different from Phase I, the disaster management policies of the second phase are highly correlated with economic development. The "focusing event" was the economic reform and opening-up policy that was implemented through the early years of this period. The reform and opening-up policy brought about political environment changes that also had substantial impacts on subsystems such as emergency management. The financial authority became increasingly important in the policy cooperation network. As the national political environment was stable and the socialist market economy system was taking shape, disaster management started to serve economic development. With the enhancement of disaster response capability and public awareness of disaster mitigation, disaster mitigation in China started to correlate with economic development and even was included in the national economic development strategy. With the growth of China's comprehensive national power, disaster mitigation was intended not only to protect people's safety and property, but also to secure economic progress. At the inauguration of the China National Committee for the International Decade for Natural Disaster Reduction, it was formally put forward that: "Disaster reduction activities should be included in the national economic development strategy", "disaster reduction should be taken as a crucial issue in social and economic development, and mainstreamed in the agendas of governments at all levels", and "disaster reduction should be considered in all of our economic activities” (Kang 2006, p. 157). 


\subsection{Phase III (2004-2008): Emerging Emergency Management System}

Phase III witnessed considerable increase in the number of disaster management policies. The major policy-making institutions, including the National Development and Reform Commission, started to get deeply involved in disaster management. In October 2003, the Third Plenary Session of the 16th Communist Party of China (CPC) Central Committee approved the Decision of the Central Committee of the Communist Party of China on Some Issues Concerning the Improvement of the Socialist Market Economy, which stressed that all forms of early warning and emergency response mechanisms should be created and improved to enhance the government's capacity to respond to emergencies and risks (CCCPC 2003). The outbreak of SARS was a "focusing event." In summarizing the experience of China's response to SARS, the Chinese leadership began to create an emergency management system centering around the formulation and revision of contingency plans, and the improvement of the emergency response system, mechanism, and legal framework (Shan 2008; Gao 2010; Zhang et al. 2011). The core of the strategy was to standardize the process of emergency response by creating the contingency plan system and then to transform, adjust, and establish the legal framework, political system, and mechanism for emergency management. Subsequently, natural hazard-induced disasters, as one of the four classifications of emergencies, were included in the overall emergency management system and became a key component in China's emergency management system. With respect to the political system, comprehensive coordinating institutions, including the National Commission for Disaster Reduction, State Flood Control and Drought Relief Headquarters, Earthquake Disaster Relief Commanding Headquarter of the State Council, National Forest Fire Prevention Headquarter, and National Nuclear Emergency Coordination Committee, were allocated the national disaster relief responsibilities. The Ministry of Civil Affairs, Ministry of Water Resources, China Earthquake Administration, and other relevant agencies remained responsible for the relief of designated types of disasters. All the local governments below the provincial level used the same organizational structure. All the ministerial departments unveiled their policies and documents on disaster management. The Ministry of Agriculture, for example, issued the Notice on Proper Disaster Prevention and Reduction in Agriculture, ${ }^{15}$ and the State Oceanic Administration issued the Notice on Further Strengthening Red Tide Disaster

\footnotetext{
15 http://www.pkulaw.cn/fulltext_form.aspx?Db=chl\&Gid=58435\&ke yword=\%e3\%80\%8a\%e 5\%85\%b3\%e4\%ba\%8e\%e $5 \% 81 \% 9 a \%$ e5\% a5\%bd \%e5\%86\%9c\%e4\%b8\%9a\%e9\%98\%b2\% $7 \% 81 \%$ be $\%$ e $5 \%$ $87 \% 8$ f\%e $7 \% 81 \%$ be $\%$ e5\%b7\%a5\%e4\%bd\%9c\%e7\%9a\%84\%e9\% $80 \% 9 a \%$ e $7 \% 9 f \% a 5 \%$ e3\% $80 \% 8 b \&$ EncodingName $=\&$ Search_Mode $=$ accurate $\&$ Search_IsTitle $=0$ (in Chinese).
}

Prevention and Reduction. ${ }^{16}$ With regard to the disaster response mechanism, in response to the principle of the Scientific Outlook on Development put forward by the Central Committee of the CPC, the Organization Department of the Central Committee issued and implemented the Pilot Scheme for Local Party Leadership and Cadre Evaluation Conforming to the Principle of Scientific Outlook on Development, which included the capacity of emergency response in the 14 performance evaluation indicators of local administrative leadership and certain leaders (ODCCCPC 2006). The capacity of emergency response indicator in the performance evaluation system facilitated the transition of local governments from focusing on GDP to a scientific development-oriented approach, which takes into account the capacity building of emergency management.

\subsection{Phase IV (2009-Present): Transition to Disaster Governance}

In Phase IV, it was proved in practice that the centralized national emergency response and disaster relief system and the capacity building of emergency management were of great importance. At the same time, the challenges from the Wenchuan Earthquake-the "focusing event" of this phase-showed that for effective disaster response, a lawbased interorganizational coordination mechanism that connects the central government, local governments, and nongovernmental organizations was necessary (Zhang et al. 2015). Actively or unknowingly, by initiating or participating in interorganizational disaster responses, nongovernmental organizations tended to assume the responsibility that a national or local government should have served. This disaster management system found no precedence but is groundbreaking, arising from the institutional environment in China. The social vulnerability and public policy dilemma resulting from the occurrence of catastrophic disasters demonstrated that the challenges were not only related to the technical capacity for disaster management, but also influenced by societal awareness of the fundamental development model and associated risks, and the responsibility of citizens in the effort to reduce risks and disaster impacts. Therefore, the Ministry of Civil Affairs unveiled the Guidance on Supporting and Guiding

\footnotetext{
$\overline{16}$ http://www.pkulaw.cn/fulltext_form.aspx?Db=chl\&Gid=128569 \&keyword=\%e3\%80\%8a\%e $5 \% 85 \%$ b3\%e4\%ba\%8e $\%$ e $8 \%$ bf $\% 9 b \%$ e4\%b8\%80\% e6\%ad\%a5\% $5 \% 8$ a\%a0\% e5\%bc\%ba\%e6\%b5\%b7\% e6\%b4\%8b\%e8\%b5\%a4\% e6\%bd\%ae\%e9\%98\%b2\% $7 \% 81 \%$ be $\%$ e $5 \% 87 \% 8$ f\% e $7 \% 81 \%$ be $\%$ e $5 \%$ b7\%a5\%e4\%bd\%9c\%e $7 \% 9$ a $\% 84 \%$ e9\%80\%9a\&EncodingName $=\&$ Search_Mode=accurate $\&$ Search IsTitle $=0$ (in Chinese).
} 
Social Forces to Participate in Disaster Relief ${ }^{17}$ in October 2015, which affirmed for the first time the importance of the participation of nongovernmental organizations and enterprises in disaster management. In December 2016, the Central Committee of the CPC and State Council issued the Recommendations on Promoting the Reform of Disaster Prevention, Reduction, and Relief Systems and Mechanisms, which further emphasized that "Disaster prevention, reduction and relief concerns the security of people's lives and properties as well as the social harmony and stability, and is a crucial gauge of leadership of the ruling party, performance of the government, mobilization of the country and cohesiveness of the nation" (CCCPC and SC 2016).

\section{Conclusion}

As shown in the analysis, the development of a disaster management system in China went through four phasesfrom focusing on agriculture, to emphasizing economic development, capacity building, and disaster governance. Each phase had distinct features that originated from the political environment, development priority, emerging emergency management system, and major natural hazardinduced disasters of the concerned period. Each phase also witnessed various revolutionary policy changes owning to political environment change and policy learning triggered by focusing events.

Although the disaster management system in China gradually switched from an approach that prioritized politics to people-oriented, the quantitative analysis of the policy documents indicates that there is still plenty of room for improvement in the future. To some extent, the formed clusters restrained the development of interdepartmental collaboration and communication. The most recent policy keyword network, for example, shows that the diversified clusters such as emergency management and disaster prevention and mitigation have not yet been integrated with each other. This indicates that it is difficult to end fragmented institutional arrangement, improve adaptive leadership (Howitt and Leonard 2009) in catastrophe response, set up fault-tolerant incentive mechanisms, and spark interdepartmental innovation and coordination. Integration and interdepartmental collaboration are still needed. Moreover, apart from departmental communication within

\footnotetext{
17 http://www.pkulaw.cn/fulltext_form.aspx?Db=chl\&Gid=258035\& keyword $=\%$ e3\%80\%8a\%e6\%b0\%91\%e6\%94\%bf\%e9\%83\%a8\% e5\% $85 \%$ b3\% $4 \%$ ba\%8e\%e6\%94\%af\%e6\%8c\%81\% $5 \%$ bc $\% 95 \%$ e $5 \%$ af $\%$ bc $\%$ e $7 \%$ a $4 \%$ be $\%$ e $4 \%$ bc $\% 9$ a $\%$ e $5 \% 8$ a $\% 9$ b\%e $9 \% 87 \% 8$ f\% $5 \%$ $8 \mathrm{f} \% 82 \%$ e4\%b8\%8e\%e6\%95\%91\% e $7 \% 81 \%$ be $\%$ e $5 \%$ b7\%a5\%e $4 \%$ bd $\% 9 c \&$ EncodingName $=\&$ Search_Mode $=$ accurate $\&$ Search_IsTi tle $=0$ (in Chinese).
}

the government, the private sector and NGOs can also be consolidated for further interaction, unified ideology, and self-evolving learning. At the same time, "risk", "disaster risk reduction", and "disaster risk governance" have not become important policy keywords, which is not in line with the global effort to move from response to risk reduction, and reduce disaster risks in transparent, inclusive, collective, and efficient ways. This means it is imperative for us to switch from disaster management to disaster risk governance. Managing risks is a defining characteristic of sustainable development. "Managing risks - rather than disasters as indicators of unmanaged risk-now has to become endogenous to the DNA of development instead of an exotic add-on that needs to be mainstreamed" (UNISDR 2015, p. 251). Knowledge sharing, advanced tools, inclusion, and trust building will contribute greatly to disaster risk governance in China.

Acknowledgements The authors appreciate the support of the National Social Science Fund of China for Outstanding Project (\#10AGL011) and the Fundamental Research Funds for the Central Universities.

Open Access This article is distributed under the terms of the Creative Commons Attribution 4.0 International License (http://crea tivecommons.org/licenses/by/4.0/), which permits unrestricted use, distribution, and reproduction in any medium, provided you give appropriate credit to the original author(s) and the source, provide a link to the Creative Commons license, and indicate if changes were made.

\section{References}

Berke, R.P., J. Kartez, and D.R. Wenger. 1993. Recovery after disaster: Achieving sustainable development, mitigation and equity. Disasters 17(2): 93-109.

Birkland, T.A. 1997. After disaster: Agenda setting, public policy, and focusing events. Washington, DC: Georgetown University Press.

Birkland, T.A. 2006. Lessons of disaster. Washington, DC: Georgetown University Press.

Birkland, T.A., and M.K. Warnement. 2013a. Defining, explaining, and testing the role of focusing events in agenda change: 30 years of focusing event theory. American Political Science Association 2013 Annual Meeting. Working paper series. 29 August-1 September 2013, Chicago, USA.

Birkland, T.A., and M.K. Warnement. 2013b. Risk and crisis management in the policy process: Permanent or evanescent concerns? In Proceedings of First International Conference on Public Policy. 26-28 June 2013, Grenoble, France. http:// archives.ippapublicpolicy.org/IMG/pdf/panel_55_s1_birkland. pdf. Accessed 18 Oct 2017.

Bonsignore, E.M., C. Dunne, D. Rotman, M. Smith, T. Capone, D.L. Hansen, and B. Shneiderman. 2009. First steps to NetViz Nirvana: Evaluating social network analysis with NodeXL. In Proceedings of International Conference on Computational Science and Engineering, Vol. 4. 29-31 August 2009, Vancouver, BC, Canada, 332-339.

Britton, N.R. 2007. National planning and response: National systems. In Handbook of disaster research, ed. H. Rodríguez, 
E.L. Quarantelli, R.R. Dynes, and K.J. Tierney, 347-367. New York: Springer.

Callon, M., J.P. Courtial, and F. Laville. 1991. Co-word analysis as a tool for describing the network of interactions between basic and technological research: The case of polymer chemistry. Scientometrics 22(1): 155-205.

Callon, M., J. Law, and A. Rip. 1986. Mapping the dynamics of science and technology. London: Macmillan Press.

Carrington, P.J., J. Scott, and S. Wasserman. 2005. Models and methods in social network analysis. New York: Cambridge University Press.

CCCPC (Central Committee of the Communist Party of China). 2003. Decision of the central committee of the communist party of China on some issues concerning the improvement of the socialist market economy. http://en.pkulaw.cn/display. aspx $?$ cgid $=49876 \& l i b=l a w$. Accessed 10 Oct 2017 (in Chinese).

CCCPC (Central Committee of the Communist Party of China) and SC (State Council). 2016. Recommendations on promoting the reform of disaster prevention, reduction, and relief systems and mechanisms. http://www.mca.gov.cn/article/zwgk/mzyw/ 201701/20170100002945.shtml. Accessed 10 Oct 2017 (in Chinese).

Chang, P.L., C.C. Wu, and H.J. Leu. 2010. Using patent analyses to monitor the technological trends in an emerging field of technology: A case of carbon nanotube field emission display. Scientometrics 82(1): 5-19.

Coulter, N., I. Monarch, and S. Konda. 1998. Software engineering as seen through its research literature: A study in co-word analysis. Journal of the Association for Information Science and Technology 49(13): 1206-1223.

Courtial, J.P. 1994. A coword analysis of scientometrics. Scientometrics 31(3): 251-260.

Cronin, B. 2001. Bibliometrics and beyond: Some thoughts on webbased citation analysis. Journal of Information Science 27(1): $1-7$.

De Bakker, F.G., P. Groenewegen, and F. Den Hond. 2005. A bibliometric analysis of 30 years of research and theory on corporate social responsibility and corporate social performance. Business \& Society 44(3): 283-317.

De Liddo, A., S.B. Shum, I. Quinto, M. Bachler, and L. Cannavacciuolo. 2011. Discourse-centric learning analytics. In Proceedings of the First International Conference on Learning Analytics and Knowledge. 27 February-1 March 2011, Banff, AB, Canada, 23-33.

Ding, Y., G.G. Chowdhury, and S. Foo. 2001. Bibliometric cartography of information retrieval research by using co-word analysis. Information Processing and Management 37(6): 817-842.

Elder, C.D., and R.W. Cobb. 1983. The political uses of symbols. New York: Longman.

English, K.M., and B. Pourbohloul. 2017. Increasing health policy and systems research capacity in low- and middle-income countries: Results from a bibliometric analysis. Health Research Policy and Systems 15(1): 64.

Freeman, L.C. 1977. A set of measures of centrality based on betweenness. Sociometry 40(1): 35-41.

Gao, X.P. 2010. The major innovation of "One Plan, Three Systems" to emergency management decision-making and organizational theory of the government. Hunan Social Sciences 5: 64-68 (in Chinese).

Gómez, I., E. Sanz, and A. Méndez. 1990. Utility of bibliometric analysis for research policy: A case study of Spanish research in neuroscience. Research Policy 19(5): 457-466.

Haddow, G.D., J.A. Bullock, and D.P. Coppola. 2008. Introduction to emergency management, 3rd edn. Burlington, MA: Elsevier.
Hansen, D., M.A. Smith, and B. Shneiderman. 2011. Eventgraphs: Charting collections of conference connections. In Proceedings of 2011 44th Hawaii International Conference on System Sciences (HICSS). 4-7 January 2011, Kauai, HI, USA, 1-10.

Henstra, D. 2011. The dynamics of policy change: A longitudinal analysis of emergency management in Ontario, 1950-2010. Journal of Policy History 23(3): 399-428.

Himelboim, I., M. Smith, and B. Shneiderman. 2013. Tweeting apart: Applying network analysis to detect selective exposure clusters in Twitter. Communication Methods and Measures 7(3-4): 195-223.

Howitt, M.A., and B.H. Leonard. 2009. Managing crises: Response to large-scale emergencies. Washington, DC: CQ Press.

Huang, C., J. Su, X. Xie, X. Ye, Z. Li, A. Porter, and J. Li. 2015. A bibliometric study of China's science and technology policies: 1949-2010. Scientometrics 102(2): 1521-1539.

Jones, B.D., F.R. Baumgartner, and J.C. Talbert. 1993. The destruction of issue monopolies in Congress. American Political Science Review 87(3): 657-671.

Kang, P.Z. 2006. Thoughts and practice of disaster prevention and mitigation since the rule of the Communist Party of China. Beijing: Peking University Press (in Chinese).

Kingdon, J.W. 2003. Agendas, alternatives, and public policies, 2nd edn. Longman Classics in Political Science. New York: Longman.

Law, J., S. Bauin, J.P. Courtial, and J. Whittaker. 1988. Policy and the mapping of scientific change: A co-word analysis of research into environmental acidification. Scientometrics 14(3-4): 251-264.

Li, W. 2008. Disasters tempered the willpower of our nation. People's Daily, 24 June 2008. http://paper.people.com.cn/rmrb/html/ 2008-06/24/nbs.D110000renmrb_14.htm. Accessed 10 Oct 2017 (in Chinese).

Lowry, W. 2006 Potential focusing projects and policy change. Policy Studies Journal 34(3): 313-335.

May, P.J. 1992. Policy learning and failure. Journal of public policy 12(4): 331-354.

MCADR (Ministry of Civil Affairs, Department of Disaster Relief). 2008. Disaster relief in 30 years. China Disaster Reduction 12: 5 (in Chinese).

MIA (Ministry of Internal Affairs, State Council). 1949. Instructions of the state council on production-oriented disaster reduction. People's Daily, 20 December 1949. http://dangshi.people.com. cn/GB/144956/10708796.html. Accessed 10 Oct 2017 (in Chinese).

MIA (Ministry of Internal Affairs, State Council). 1950. Supplementary instructions on production-oriented disaster reduction. People's Daily, 4 January 1950. http://dangshi.people.com.cn/ GB/144956/10708797.html. Accessed 10 Oct 2017 (in Chinese).

Mohammad, S., C. Dunne, and B. Dorr. 2009. Generating highcoverage semantic orientation lexicons from overtly marked words and a thesaurus. In Proceedings of the 2009 Conference on Empirical Methods in Natural Language Processing, Vol. 2. 6-7 August 2009, Singapore, 599-608.

Newman, M.E.J. 2004. Detecting community structure in networks. European Physical Journal B 38(2): 321-330.

ODCCCPC (Organization Department of the Central Committee of the Communist Party of China). 2006. Conform to scientific outlook on development and build high-quality cadre team: Pilot scheme for local party leadership and cadre evaluation conforming to the principle of scientific outlook on development. People's Daily, 7 July 2006. http://58.68.146.102/rmrb/ 20060707/1. Accessed 10 Oct 2017 (in Chinese).

Osareh, F. 1996. Bibliometrics, citation analysis and co-citation analysis: A review of literature I. Libri 46(3): 149-158. 
Pagel, P.S., and J.A. Hudetz. 2011. An analysis of scholarly productivity in United States academic anaesthesiologists by citation bibliometrics. Anaesthesia 66(10): 873-878.

Pilkington, A., and J. Meredith. 2009. The evolution of the intellectual structure of operations management-1980-2006: A citation/co-citation analysis. Journal of Operations Management 27(3): 185-202.

Porfir'ev, B.N. 1998. Disaster policy and emergency management in Russia. Hauppauge, NY: Nova Science Publishers.

Real-Dato, J. 2009. Mechanisms of policy change: A proposal for a synthetic explanatory framework. Journal of Comparative Policy Analysis: Research and Practice 11(1): 117-143.

Sabatier, P.A. 1987. Knowledge, policy-oriented learning, and policy change: An advocacy coalition framework. Knowledge 8(4): 649-692.

Sabatier, P.A. 1988. An advocacy coalition framework of policy change and the role of policy-oriented learning therein. Policy Sciences 21(2): 129-168.

Sabatier, P.A., and H. Jenkins-Smith. 1993. Policy change and learning: An advocacy coalition framework. Boulder, CO: Westview.

Shan, C.C. 2008. Build the emergency response management system with Chinese characteristics. Journal of China Executive Leadership Academy Pudong 2(5): 12-18 (in Chinese).

Shneiderman, B., and C. Dunne. 2012. Interactive network exploration to derive insights: Filtering, clustering, grouping, and simplification. In Proceedings of 2012 Redmond International Symposium on Graph Drawing, 2-18. Berlin: Springer.

Smith, M.A., B. Shneiderman, N. Milic-Frayling, E. Mendes Rodrigues, V. Barash, C. Dunne, T. Capone, A. Perer, and E. Gleave. 2009. Analyzing (social media) networks with NodeXL. In Proceedings of the Fourth International Conference on Communities and Technologies. 25-27 June 2009, University Park, PA, USA, 255-264.
Tierney, K.J. 2007. Businesses and disasters: Vulnerability, impacts, and recovery. In Handbook of disaster research, ed. H. Rodríguez, E.L. Quarantelli, R.R. Dynes, and K.J. Tierney, 275-296. New York: Springer.

UNISDR (United Nations International Strategy for Disaster Reduction). 2015. Global assessment report on disaster risk reduction 2015. http://www.preventionweb.net/english/hyogo/gar/2015/en/ home/download.html. Accessed 10 Oct 2017.

Wagner, C.S., and L. Leydesdorff. 2005. Mapping the network of global science: Comparing international co-authorships from 1990 to 2000. International Journal of Technology and Globalisation 1(2): 185-208.

Will, P.E. 1990. Bureaucracy and famine in eighteenth-century China. Redwood City, CA: Stanford University Press.

Zhang, G.Y. 2003. Witness the flood of the huai river in 1975. Yanhuangchunqiu 1: 14-21 (in Chinese).

Zhang, Q. 2015. Disaster governance in a rising power: China's response to the 2008 Wenchuan and 2013 Lushan earthquakes. Beijing: Peking University Press (in Chinese).

Zhang, Q., and H. Zhang. 2008. Decision-making dilemma in the response to catastrophes: A case study of 512 Wenchuan Earthquake. Journal of Literature, History and Philosophy 5: 20-27 (in Chinese).

Zhang, Q., Q.B. Lu, Y.M. Hu, and J. Lau. 2015. What constrained disaster management capacity in the township level of China? Case studies of Wenchuan and Lushan earthquakes. Natural Hazards 77(3): 1915-1938.

Zhang, Q., Q.B. Lu, and X. Zhang. 2011. An outlook on the Chinese model of emergency management based upon the review of the Wenchuan Earthquake response: An interactive perspective of strong state and strong society. Chinese Public Administration 5: 50-56 (in Chinese).

Zou, M., and Y. Yuan. 2010. China's comprehensive disaster reduction. International Journal of Disaster Risk Science 1(1): 24-32. 